\title{
Influências e efeitos do PNAE na agricultura familiar em São Lourenço do Sul
}

\author{
Edilene dos Santos Corrêa ${ }^{1}$ \\ Daniela Garcez Wives ${ }^{2}$
}

\begin{abstract}
Resumo
Este trabalho busca olhar o mercado institucional sob a perspectiva dos agricultores e tem como base a análise de sistemas, partindo do pressuposto de que o desenvolvimento rural ocorre através de arranjos entre atores locais e de outras esferas como regional, estadual e nacional. Estes arranjos formam sistemas onde uma das engrenagens é a comercialização. Reconhecendo a importância do acesso a mercados no processo de reprodução social da agricultura familiar fomos pesquisar o Programa Nacional de Alimentação Escolar (PNAE) e suas influências nas unidades de produção agrícola. Esta pesquisa se propõe a analisar as características e como estão organizadas a produção, a família e a comercialização nas unidades de produção da agricultura familiar fornecedoras de alimentos para o PNAE. Trata-se de um estudo de caso no município de São Lourenço do Sul. Foi adotada a metodologia predominantemente qualitativa. As ferramentas de coleta de dados foram painel de especialistas, entrevistas semiestruturadas e categorização a partir de tipologia, contando com adaptação da ferramenta MESMIS. Foram identificados os sistemas de produção de base ecológica, convencional e agroindustrial. Constatamos que o PNAE impacta na organização da família, por exemplo, remetendo ao empoderamento feminino e gerando mudança na relação do jovem com a produção agropecuária. Também identificamos mudanças na organização da produção especialmente na adoção de técnicas diferentes e na organização da comercialização. Ao final notamos que o PNAE provoca mudanças, constitui-se como oportunidade e apresenta desafios para os agricultores familiares.
\end{abstract}

Palavras-chave: PNAE. Agricultura familiar. Sistemas de produção.

\begin{abstract}
This paper seeks to look at the institutional market from the perspective of farmers and is based on systems analysis, assuming that rural development takes place through arrangements between local actors and other spheres as regional, state and national. These arrangements form systems where one of the gears is marketing. Recognizing the importance of access to markets in the process of social reproduction of family farming were searching the National School Feeding Programme (PNAE) and their influence on agricultural production units. This research aims to analyze the characteristics and how they are organized production, the family and the commercialization of the production units of family farming supply of food for the PNAE. This is a case study in São Lourenço do Sul. Predominantly qualitative methodology was adopted. The data collection tools were expert panel, semistructured interviews and categorization from typology., With adaptation of MESMIS tool. the ecologically-based production systems, conventional and agroindustrial were identified. We note that the PNAE impact on family organization, for example, referring to women's empowerment and generating change in the young man's relation to agricultural production. We also identified changes in the organization of production especially in the adoption of different techniques and marketing organization. At the end we note that the PNAE causes changes, constitutes an opportunity and presents challenges for family farmers.
\end{abstract}

Keywords: PNAE. Family farming. Production systems.

\footnotetext{
1 Mestre em Desenvolvimento Rural pela Universidade Federal do Rio Grande do Sul (PPGDR-UFRGS). escsls@yahoo.com.br

2 Doutora em Desenvolvimento Rural (UFRGS) e Pós-Doutoranda em Desenvolvimento Rural (PPGFR-UFRGS). Professora colaboradora do Programa de Pós-Graduação em Desenvolvimento Rural (PGDR) da UFRGS. garcezd@gmail.com
}

COLÓQUIO - Revista do Desenvolvimento Regional - Faccat - Taquara/RS - v. 15, n. 1, jan./jun. 2018 


\section{Introdução}

Pensar o desenvolvimento rural no âmbito da agricultura familiar (AF) nos remete à uma de suas dimensões, a comercialização dos produtos, pois, isso implica, em certa medida, na qualidade de vida dos agricultores, no investimento necessário para a manutenção das atividades produtivas e na sua reprodução social. Estudos como os de Agne (2010), Nazzari, Bertolini e Brandalise (2007), apontam o acesso ao mercado e à comercialização de produtos da agricultura familiar como um dos principais desafios desta categoria de produtores. Categoria esta que, conforme apresentado por Sabourin, Samper e Massadier (2015), correspondem, na América Latina e Caribe, a cerca de 17 milhões de unidades produtivas, agrupando uma população de 60 milhões de pessoas.

No que tange ao desafio de comercializar, no cenário da AF brasileira observa-se atualmente o fortalecimento do papel dos mercados institucionais, que em alguma medida têm minimizando obstáculos para a comercialização dos produtos da agricultura familiar. Enquanto mercado institucional recente, voltado aos agricultores familiares, pode-se destacar o Programa Nacional de Alimentação Escolar (PNAE).

Para que possamos compreender um pouco da realidade pesquisada, convém descrever de forma sucinta São Lourenço do Sul, município que possui 43.111 habitantes, destes, 21.495 são mulheres e 21.619 são homens, 18.874 residem na zona rural e 24.327 na zona urbana, tem uma área de extensão territorial de $2.036,12 \mathrm{Km}^{2}$, densidade demográfica de 21,17 habitantes por $\mathrm{Km}^{2}$. São Lourenço do Sul está localizado na parte centro-sul do Rio Grande do Sul, distante 165 Km da capital Porto Alegre. Situa-se na margem oeste da Laguna dos Patos, entre a capital do Estado, Porto Alegre e Pelotas, cidade de grande relevância regional (IPEA, 2010). Quanto a questão fundiária pode-se dizer que São Lourenço têm quase $100 \%$ de suas área distribuída em pequenos e médios estabelecimentos de agricultores familiares.

O município de São Lourenço do Sul iniciou a compra de alimentos da agricultura familiar antes mesmo da exigência legislação, a iniciativa se desenvolveu por meio de um trabalho organização e inclusão dos alimentos produzidos pelos agricultores locais na 
merenda escolar. Para tanto houve um movimento de estímulo da Agricultura Familiar, em diversas esferas e com diversos atores, por meio de atividades como palestras e oficinas com agricultores, a nutricionista, as merendeiras, com alunos e principalmente com a comunidade escolar. Estas atividades primavam por ressaltar a qualidade dos alimentos, valorizar a agricultura familiar e principalmente sua íntima relação para o desenvolvimento da cidade visto que trata-se de um município com características essencialmente agrícolas. Assim, São Lourenço do Sul é considerado precursor na compra de produtos da agricultura familiar para alimentação escolar, no Rio Grande do Sul, o que o tornou um importante modelo para outros municípios do entorno, conforme dados da Secretaria Municipal de Educação, Cultura e Desporto (SMECD). Concebendo que os princípios fundamentais do programa abrangem a valorização da produção local, o respeito aos hábitos alimentares saudáveis e aos costumes alimentares tradicionais das diferentes regiões do país trabalhando com essas temáticas a AF e a segurança alimentar e nutricional (SAN).

O PNAE teve como marco legal no ano de 2009 , através da Lei 11.947 , que institui a obrigatoriedade de adquirir no mínimo $30 \%$ do valor repassado, pelo Fundo Nacional de Desenvolvimento da Educação (FNDE) aos municípios, estado e distrito federal, de produtos da AF, com dispensa de licitação pública (PEIXINHO, 2013). Os valores repassados pelo FNDE à conta do PNAE têm aumentado a cada ano, mesmo quando o número de estudantes diminui. Isto se deve, principalmente, ao aumento do valor/aluno/ano, à implementação da Educação de Tempo Integral, do Programa Mais Educação ${ }^{3}$ e à inclusão dos estudantes de Educação de Jovens e Adultos no repasse de recursos para alimentação escolar.

Esse investimento possibilita que diferentes resultados venham a aparecer, como a permanência dos agricultores no campo, aumento do número de jovens voltados à $A F$, melhorias na preservação do ambiente, aumento da renda de agricultores familiares e melhoria na qualidade de vida das famílias produtoras, a partir do manejo na produção e do consumo de alimentos mais saudáveis, no caso da produção de agroecológicos (TRICHES,

\footnotetext{
3 O Programa Mais Educação, instituído pela Portaria Interministerial no 17/2007 e regulamentado pelo Decreto 7.083/10, constitui-se como estratégia do Ministério da Educação para induzir a ampliação da jornada escolar e a organização curricular na perspectiva da Educação Integral. Os estudantes das escolas que aderem ao programa passam a permanecer na escola no turno inverso para a realização de atividades extracurriculares e recebem, neste período, em geral, mais três refeições. Fonte: http://portal.mec.gov.br.
}

COLÓQUIO - Revista do Desenvolvimento Regional - Faccat - Taquara/RS - v. 15, n. 1, jan./jun. 2018 
SCHNEIDER, 2010). Tais argumentos convergem para a manutenção de uma categoria de agricultores que é reconhecida como "a forma predominante de agricultura no setor de produção de alimentos" (FAO, 2016, p. 35).

Nesse contexto nos propomos a refletir sobre o PNAE sob a perspectiva dos agricultores familiares beneficiados por este mercado institucional tendo como objetivo geral analisar as influências e os efeitos das compras governamentais nas formas de organização da produção, da família e da comercialização adotadas pelos agricultores nas propriedades rurais fornecedoras de produtos agrícolas para o PNAE.

\section{Segurança alimentar e nutricional (SAN) e o PNAE}

A segurança alimentar, cujo conceito está em constante elaboração, pautado em discussões, permeia espaços nacionais e internacionais de planejamento para o desenvolvimento das nações, uma vez que a questão da fome ainda é um grande problema para humanidade (BELIK, 2003; TRICHES; SCHNEIDER, 2010).

Belik (2003) chama a atenção para o fato de que acesso a alimentos é bem diferente de disponibilidade de alimentos e que a segurança alimentar está atrelada ao acesso, à qualidade dos alimentos e à possibilidade de consumi-los dignamente. Bem como, a regularidade com acesso contínuo que garanta as necessidades nutricionais básicas para o desenvolvimento e saúde do organismo humano.

Enfatiza Maluf (1999) que uma das modificações do PNAE consiste na sistemática de compras da agricultura familiar, as quais são consideradas fundamentais para o desenvolvimento econômico local, sendo muito importante para efetividade da segurança alimentar que depende "da criação dos espaços institucionais adequados à articulação de iniciativas em áreas bastante diversas e da subordinação a um objetivo de natureza social das políticas e programas que o afetam direta ou indiretamente, em especial no campo econômico" (MALUF, 1999, p. 17).

O PNAE visto como mola propulsora do desenvolvimento rural faz parte da política de desenvolvimento territorial, dialogando com o Sistema Nacional de Segurança Alimentar 
e Nutricional, especialmente no que se refere à adoção de políticas e ações que levem em conta as dimensões ambiental, cultural, econômica, regional e social.

Entre os objetivos do PNAE está o de suprir as necessidades nutricionais dos alunos durante sua permanência na escola, garantindo uma alimentação saudável, segura, de qualidade e em quantidade adequada. Visando contribuir para uma melhor aprendizagem e aproveitamento escolar, bem como, formar hábitos alimentares saudáveis através de um processo de educação alimentar e buscar sintonia com hábitos alimentares locais e regionais.

Em relação aos impactos econômicos do PNAE, podemos citar o fomento à economia local e regional a partir da ampliação das condições de acesso aos alimentos por meio da produção oriunda da agricultura familiar. Com as unidades executoras do programa utilizando a ferramenta de aquisição de alimentos por Declaração de Aptidão ao Programa de Financiamento da Agricultura Familiar, vem ocorrendo um estímulo ao acesso a crédito e ao desenvolvimento econômico das famílias que produzem alimentos (KLUCK; GAZOLLA, 2014).

O aspecto ambiental do Programa PNAE está pautado na valorização da produção agroecológica contribuindo para a conservação da biodiversidade e a utilização sustentável dos recursos, estimulando assim os agricultores e os estudantes das redes municipal e estadual a adquirirem hábitos de vida mais saudáveis. Assim como previsto pelo PNAE, a FAO em estudo realizado em oito países das Américas Central e do Sul aponta benefícios de programas vinculados à alimentação escolar para os estudantes, que vão além do consumo do alimento e das questões nutricionais, é uma prática pedagógica, um momento de promover integração social e compartilhar os diversos saberes da vida em sociedade.

O controle social do programa é realizado por membros que compõem em nível estadual o Conselho Estadual de Alimentação Escolar - CEAE e na esfera municipal o Conselho Municipal de Alimentação Escolar - CAE, o conselho deve acompanhar a execução físico-financeira do programa. De modo geral, pesquisas apontam para os benefícios do consumo dos alimentos orgânicos pelos estudantes, a conservação do meio ambiente e melhoria da qualidade de vida e saúde dos agricultores. Podemos considerar que, mercados podem ser examinados como estruturas sociais, levando em conta a subjetividade dos agentes econômicos, a diversidade e a história de suas formas de coordenação, bem como 
as representações a partir das quais os atores envolvidos no processo se relacionam uns com os outros, a sua capacidade de obter e inspirar confiança, de negociar, fazer cumprir contratos, estabelecer e realizar direitos (ABRAMOVAY, 2014).

Em suma, os mercados institucionais têm se mostrado estruturas de estímulo ao enfrentamento de fragilidades dos agricultores familiares, são canais de comercialização criados através de políticas públicas, ou seja, instrumentos de intervenção do estado como forma de promoção do desenvolvimento rural e fortalecimento da agricultura familiar.

\section{Metodologia}

A pesquisa realizada nesse município tem caráter exploratório. Segundo Gil (2010), a pesquisa exploratória possui como objetivo fundamental o aprimoramento de ideias ou a descoberta de instituições, tendo o planejamento flexível, possibilitando assim, a consideração de diversos aspectos relativos ao objeto de estudo.

Visando criar condições mais favoráveis para o trabalho de campo, optou-se pela realização de um painel de especialistas como etapa inicial de levantamento de dados. Os dez colaboradores do painel de especialistas foram: a técnica e a nutricionista responsáveis pelo Setor de Alimentação Escolar da Secretaria Municipal de Educação; o extensionista Engenheiro Agrônomo do Centro de Apoio ao Pequeno Agricultor (CAPA); três agricultores familiares, lideranças de três localidades ${ }^{4}$ distintas que acumulam a função de coordenadores dos grupos formais e informais aos quais pertencem; a técnica - Auxiliar Administrativa da Cooperativa Mista dos Pequenos Agricultores da Região Sul Ltda. (COOPAR); o extensionista rural nível social I em agropecuária - Engenheiro Agrônomo da Empresa de Assistência Técnica e Extensão Rural do Rio Grande do Sul - Associação Sulina de Crédito e Assistência Rural (Emater/RS-ASCAR) e dois Técnicos em Agropecuária da Cooperativa Sul Ecológica.

Com base no retrato da realidade identificado pelos especialistas foi elaborado um questionário semiestruturado para realização de entrevista nas UPAs. As questões

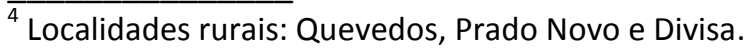

COLÓQUIO - Revista do Desenvolvimento Regional - Faccat - Taquara/RS - v. 15, n. 1, jan./jun. 2018
} 
abordaram os sistemas social e produtivo observando, em linhas gerais, o antes e o depois do PNAE para as famílias de agricultores. Foram selecionadas, aleatoriamente as UPAs, com o cuidado para que estas representassem a média das realidades encontradas no universo de famílias fornecedoras de alimentos para o PNAE, excluindo os casos extremos.

Foram entrevistadas três unidades do Tipo 1 - sistema de produção de base ecológica, quatro do Tipo 2 - sistema de produção convencional e quatro do Tipo 3 sistema agroindustrial, todas da agricultura familiar, fornecedores de produtos para a alimentação escolar de São Lourenço do Sul. O Quadro 1, abaixo, apresenta o resumo desta tipologia. A interpretação do conteúdo obtido foi realizada em três etapas dentre as consideradas básicas: pré-análise; exploração do material e tratamento dos dados e interpretação (GIL, 2010; MINAYO, 2011).

Quadro 1 - Quadro da tipologia da agricultura familiar inserida no PNAE

\begin{tabular}{|c|c|c|c|}
\hline Categorias de análise & Tipo 1 & Tipo 2 & Tipo 3 \\
\hline Sistema de produção & Base Ecológica & Convencional & Agroindustrial \\
\hline especialização & $\begin{array}{c}\text { Maior diversificação } \\
\text { da produção }\end{array}$ & $\begin{array}{c}\text { Menor diversificação da } \\
\text { produção com } \\
\text { tendência à } \\
\text { especialização }\end{array}$ & Especialização \\
\hline Autoconsumo* & $\begin{array}{c}\text { Menor dependência } \\
\text { do mercado para } \\
\text { autoconsumo }\end{array}$ & $\begin{array}{c}\text { Maior dependência do } \\
\text { mercado para } \\
\text { autoconsumo }\end{array}$ & $\begin{array}{c}\text { Maior dependência } \\
\text { do mercado para } \\
\text { autoconsumo }\end{array}$ \\
\hline $\begin{array}{c}\text { Organização para a } \\
\text { comercialização }\end{array}$ & $\begin{array}{c}\text { Comercialização } \\
\text { através de grupo } \\
\text { informal, } \\
\text { agroindústria familiar } \\
\text { e cooperativa. }\end{array}$ & $\begin{array}{c}\text { Comercialização } \\
\text { e de grupo informal. }\end{array}$ & $\begin{array}{c}\text { Comercialização } \\
\text { através de } \\
\text { agroindústria } \\
\text { familiar e } \\
\text { cooperativa. }\end{array}$ \\
\hline
\end{tabular}

Fonte: Dados coletados através de Painel de Especialistas, tipologia elaborada pela autora (2013).

* Para esta categoria de análise, diante das informações obtidas, foi considerada a influência do mercado na decisão sobre o autoconsumo, as entrevistas nas UPAs mostraram que em alguns casos a prioridade é atender ao mercado, ficando condicionado o autoconsumo para os casos de sobra do alimento.

Quanto ao tratamento das informações de cunho qualitativo, houve a compilação e a análise de dados por meio de adaptação da ferramenta Marco para laEvaluación de Sistemas COLÓQUIO - Revista do Desenvolvimento Regional - Faccat - Taquara/RS - v. 15, n. 1, jan./jun. 2018 
de Manejo de Recursos Naturales (MESMIS) ${ }^{5}$. Segundo Astier (2009), o MESMIS mostra-se útil para discutir sobre fortalezas e debilidades dos sistemas e sistematizar experiências. A utilização da metodologia MESMIS ao analisar dimensões ambiental, econômica e social permite explorar aspectos específicos da realidade local.

\section{Apresentação e análise comparativa dos dados}

Entre as variáveis do aspecto social, a respeito da sucessão familiar, constatamos que os filhos que saíram para estudar continuam atuando na agricultura e nas agroindústrias nos dias em que estão em casa e todos têm a intenção de atuar na UPA aplicando os conhecimentos de suas áreas de formação. "Antes a filha não ajudava, agora, sábados à tarde tem vindo ajudar. O lado positivo é que assim os filhos se envolvem e têm a visão de que é um bom mercado" (AGRICULTORA UPA ' $I$ ').

Conforme percebemos a sucessão familiar é mais perceptível e já se mostra consolidada em $100 \%$ no sistema de produção convencional. No sistema de produção agroindustrial está o segundo maior índice de sucessão familiar correspondente a $75 \%$ dos casos. E, por fim, no sistema de base ecológica, em $66 \%$ dos casos há a sucessão familiar perceptível. Identificamos que dois dos motivadores mais significativos são os laços familiares fortes e o entendimento por parte dos jovens de que a atividade agrícola é rentável.

No que se refere aos momentos de descanso e lazer, nenhuma das famílias tiram férias, mas todos os entrevistados reservam tempo para atividades relacionadas à convivência e interação social seja entre o grupo familiar ou entre os membros da

\footnotetext{
${ }^{5}$ O MESMIS é um projeto de avaliação de sustentabilidade de agroecossistemas criado em 1995 pelo Grupo Interdisciplinar de Tecnologia Rural Apropriada (GIRA) (México) (MASERA; ASTIER; LÓPEZ-RIDAURA, 2000 apud FERREIRA, 2009). O MESMIS tem respondido a carência por métodos de análise de dados qualitativos, os métodos convencionais geralmente são inadequados diante da existência de variáveis não quantificáveis. Trata-se de uma ferramenta metodológica que ajuda a avaliar a sustentabilidade de sistemas de manejo de recursos naturais, com ênfase no contexto de produtores campesinos em âmbito local de uma amostra ou da comunidade num todo; apresenta uma estrutura flexível adaptável a diferentes níveis de informação e capacidade técnica. Operacionalmente, são definidos uma série de pontos forte e fracos para a interpretação do sistema que se quer analisar os quais se relacionam com as três áreas de avaliação, ambiental, social e econômica. Para cada área de avaliação são definidos critérios de diagnóstico e indicadores (FERREIRA, 2009).
}

COLÓQUIO - Revista do Desenvolvimento Regional - Faccat - Taquara/RS - v. 15, n. 1, jan./jun. 2018 
comunidade. A interação social aparece em outras duas variáveis 'capacitações' e 'participação social', quanto à primeira, todos os tipos de UPAs participam de cursos, porém, pertencem ao grupo de entrevistados do sistema agroindustrial os agricultores que mais procuram por cursos. Quanto à 'participação social', nota-se que em todos os tipos há o envolvimento com a comunidade através da participação em associações de produtores e/ou de moradores das localidades e que todos têm laços com cooperativas e sindicatos. Além disso, em menor proporção, mas também abrangente a todos os tipos de sistemas adotados pelos agricultores aparece a participação em grupos informais de agricultores para a comercialização, sendo um deles o grupo de produtores orgânicos 'Grupo Ecológico do Prado Novo'.

Uma peculiaridade que não aparece explicitamente dentre as variáveis apresentadas, mas que ao conviver com as famílias foi possível observar é que a tomada de decisões na gestão das unidades é compartilhada entre os integrantes. Assim, segundo Carneiro (1999) e Wives (2013), se mantém, em termos conceituais, o caráter familiar da produção, pois, os integrantes da família desenvolvem o papel de administradores e de trabalhadores, ou seja é no núcleo familiar que os objetivos e as decisões para atingi-los são traçadas.

Sob as lentes da dimensão de cunho ambiental é possível observarmos que nas variáveis "adubação" e "manejo de solo" tanto no sistema de base ecológica quanto no convencional aparecem adubação verde, cobertura morta, adubação com esterco e rotação de culturas. $\mathrm{O}$ que, vinculado com o fato de que todos os entrevistados mencionaram ter consciência da importância de estar produzindo para crianças comerem na escola, pode ser indício de uma preocupação maior com a qualidade do que está sendo produzido.

Um dos agricultores do sistema convencional, em virtude de estar fornecendo alimentos para a alimentação escolar, foi mudando suas práticas, minimizando o uso de produtos químicos e, atualmente, possui estufas experimentais de produção orgânica. Esta UPA não se autointitula como 'em transição', nem considera sua produção como de base ecológica, mas caminha para esta transição e confirma a afirmação de Wives (2013) de que há uma revisão das formas de produção impulsionada pela agricultura ecológica, onde se produz em busca de desenvolvimento, preservando os recursos naturais. Ainda quanto aos 
recursos naturais, verificamos que nem todas as UPAs possuem Reservas Legais (RLs) e Áreas de Preservação Permanentes (APPs), que para alguns agricultores são apenas áreas que apenas existem, para outros são consideradas importantes e para outros ainda, são áreas muito importantes.

Quanto às variáveis de cunho econômico como mão-de-obra, na maioria dos casos, predomina a estritamente familiar e quando ocorre contratação esta é sob o regime de diarista e não contratação permanente de funcionários. Em linhas gerais, economicamente tanto o autoconsumo que aparece em todas as UPAs, quanto a comercialização dos produtos da agricultura familiar para alimentar estudantes, impactam. Porém, o consumo de alimentos, seja pelos agricultores ou pelo estudantes diariamente, convergem para o que defende Belik (2003) e para o que está previsto na Constituição Federal, ou seja, o direito humano à alimentação adequada.

Na variável "canais de comercialização" é comum a todos os tipos de sistema de produção, além do acesso ao PNAE, a comercialização em feira livre e a venda direta ao consumidor, que representam as distintas formas de comercialização que formam as relações mercantis conforme tratado por Conterato et al. (2011). Podemos observar os mercados mais acessados a partir da Figura 1, neste comparativo notamos que o mercado institucional apresenta a equidade do universo da pesquisa que buscou UPAs que fornecem para o PNAE, no entanto, podemos perceber que no acesso aos três tipos de mercado identificados, o sistema agroindustrial alcança todos em uma proporção maior do que os demais sistemas produtivos. Identificamos que o mercado informal é pouco acessado pelo sistema convencional, que é o único a acessar em 100\% o mercado formal. Já para o sistema de base ecológica os mercados que aparecem como mais significativos são o institucional e o informal. 
Figura 1 - Tipos de mercado acessados através dos canais de comercialização mais utilizados pelos agricultores



Fonte: Elaborada pela autora com base nos dados de campo (2014).

Durante a pesquisa foram presenciados momentos de demanda do consumidor para os agricultores inclusive no momento de entrega dos produtos no setor de alimentação escolar. Eis a capacidade de inspirar confiança, negociar e de cumprir contratos que caracteriza mercado para Abramovay (2004). Esta prática de interação que forma o mercado é conceituada por Conterato et al. (2011), onde há interfaces entre atores sociais e o contexto em que vivem e suas relações formam redes sociais, que naquele modo e espaço de ação recíproca, resultam no comércio. Estas concepções são identificadas não apenas na situação de venda direta descrita no parágrafo anterior, mas também quando os agricultores se organizam formalmente para concorrer na chamada pública e quando combinam informalmente como e quem do grupo de cada localidade vai efetuar a entrega dos produtos.

No que se refere à "organização da produção", ao questionar e observar a realidade das UPAs se constatou que foram necessárias algumas adequações. Como exemplo, o direcionamento da produção para os produtos mais solicitados nas chamadas públicas. Com isto, no caso da produção pelo sistema de base ecológica, houve maior diversificação da COLÓQUIO - Revista do Desenvolvimento Regional - Faccat - Taquara/RS - v. 15, n. 1, jan./jun. 2018 
produção, o que, conforme relatado pelos entrevistados contribui muito para a saúde da família. Já no caso da produção pelos sistemas convencional e agroindustrial há tendência à especialização, "A gente focou mais em produtos que rodam mais, deixamos de fazer compotas e cocada para focar mais nas bolachas" (AGRICULTORA DA UPA 'I').

Também houveram mudanças nas técnicas de cultivo, como implantação de sistemas de irrigação, construção de estufas, utilização de sombreamento dos canteiros e aquisição de equipamentos (como enxada rotativa na produção agrícola e extrusora ${ }^{6}$ na produção agroindustrial). Segundo a maioria dos entrevistados, em virtude deste mercado institucional, houve melhoria no planejamento e tem ocorrido maior organização da produção para que possam atender a demanda. Dessa forma, como argumenta Dufumier (2007), é de fundamental importância identificar a coerência e a complexidade interna dos sistemas de produção, bem como as relações de sinergia ou de complementariedade, pois de tal forma utilização dos recursos tente a estar articuladas tanto com os fatores internos a UPA como externos.

Quanto à "organização da família" em função do PNAE, em linhas gerais, foram mencionadas como mudanças em virtude deste mercado institucional, a melhoria na qualidade de vida, seja pela diversidade de alimentos para o autoconsumo, pela satisfação de produzir alimentos para as crianças ou pelo aumento da renda familiar. Com o PNAE, "Dá diferença, melhorou bastante economicamente” (AGRICULTORA DA UPA 'J'). Há a conscientização por parte do agricultor, de que os alimentos serão consumidos pelos filhos e sobrinhos na escola, o que dialoga com a concepção de que a AE é um serviço importante prestado à população que está atrelado à cidadania e conforme Carvalho e Castro (2009). Neste sentido, se observou que junto com a consciência de estar produzindo para alimentar crianças, há o sentimento de estar sendo valorizado, o que foi apontado também por Triches, Gerhardt e Schneider (2014) ao constatar que existe reavaliação dos produtos e dos produtores que fornecem para o PNAE. Eis um relato que demonstra o acima exposto e remete aos princípios da SAN, alimentos mais saudáveis para as crianças das escolas e para a

\footnotetext{
${ }^{6}$ Máquina que permite moldar uniformemente biscoitos e possibilita maior rendimento na produção, segundo a agricultora, com esta máquina foi possível obter uma linha de produção muito rápida que resulta em um produto muito mais bonito.
}

COLÓQUIO - Revista do Desenvolvimento Regional - Faccat - Taquara/RS - v. 15, n. 1, jan./jun. 2018 
família, consequentemente melhoria na qualidade de vida: "Às vezes sentamos para almoçar e dizemos: de tudo que tem na mesa só o sal não é da propriedade, o resto tudo produzimos aqui" (AGRICULTOR DA UPA 'C'). Para as agroindústrias a organização da família também se fez diferente, como participação dos filhos na atividade produtiva, maior envolvimento de todos na produção e estabelecimento de prioridades como exemplifica esta declaração: "Precisa priorizar algumas coisas, o que é menos urgente fica para depois" (AGRICULTORA DA UPA ' $K$ ').

A organização da família apresentou ainda mudanças como o envolvimento maior por parte dos homens na produção de hortaliças foi mencionado nas entrevistas, assim como a participação dos jovens e crianças (possibilitando o aprendizado de técnicas de cultivo e manejo de culturas), a autonomia das mulheres e a mudança nas relações de poder (na produção de frutas, verduras e legumes, por exemplo, o dinheiro passou a ser das mulheres e não de seus maridos). Outra mudança identificada foi o fato das tarefas domésticas passarem a ser executadas pelos homens (marido e filho). Para Siliprandi e Cintrão (2015), em muitas regiões é habitual que as mulheres não disponham de renda própria, com isto, se vendo obrigadas a pedir dinheiro para o marido até mesmo para necessidades de manutenção da casa.

Sobre a "organização da comercialização", o principal diferencial é a programação de entrega de alimentos. Para atender a venda programada das chamadas públicas, os agricultores passaram a fazer um planejamento para conseguirem atender em qualidade, em quantidade e em tempo a demanda da rede municipal de ensino. "É preciso se programar para atender esta venda garantida. Antes de vender pro PNAE tinha que entregar mais pingado (os morangos)." (AGRICULTOR DA UPA 'G'). Também se organizaram para facilitar a logística de entrega dos alimentos.

“Tem que levar sempre a produção até a coordenadora da localidade, ela é que vai entregar na cidade, na merenda escolar (setor da prefeitura) todas as semanas. Até porque temos só uma moto, não dá para entregar os produtos assim, agora nosso objetivo é comprar um veículo" (AGRICULTORA DA UPA 'A'). 
Pelo visto até aqui e pelos depoimentos acima (UPAs ' $A$ ', ' $G$ ' e ' $F$ ') podemos constatar que o PNAE trouxe incentivo à organização e à cooperação e representa uma garantia de venda dos produtos aumentando ou ao menos oferecendo segurança quanto à renda da família.

Ao pesquisar a influência ou não do PNAE na organização das UPAs surgiram relatos sobre as vantagens e as dificuldades encontradas pelos agricultores ao acessar este mercado. As Figuras 2 e 3, a seguir, apresentam as principais vantagens e as principais dificuldades do PNAE para os agricultores.

\section{Figura 2 - Principais vantagens do PNAE para a AF}

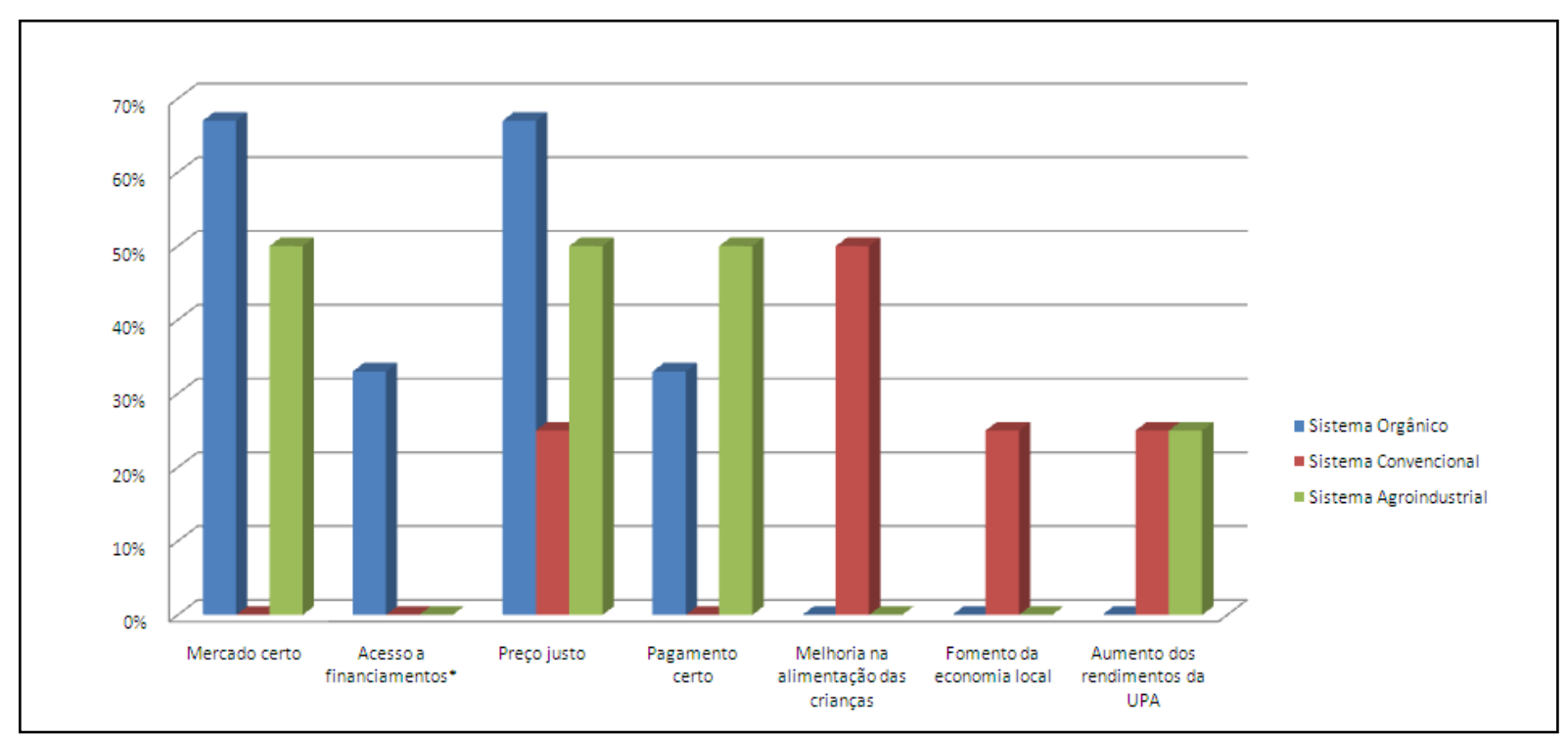

Fonte: Elaborada pela autora com base nos dados de campo (2014).

Porém, mesmo o PNAE sendo reconhecido pelos entrevistados como um mercado vantajoso, as dificuldades existem e estão postas como desafios para a melhoria da execução desta ferramenta de desenvolvimento da agricultura familiar. Quanto às dificuldades mais apontadas estão a carência por assistência técnica e a burocracia que segundo os entrevistados existe em excesso. Foram identificados ainda problemas com a logística de entrega dos produtos, a necessidade de aumento no valor máximo anual por agricultor e a suscetibilidade de influência de fatores climáticos a que ficam expostas as produções agrícolas. Como notamos, os agricultores identificam os gargalos da execução 
deste mercado institucional, o que possibilita refletirmos sobre um cenário futuro mais favorável.

Figura 3 - Principais dificuldades do PNAE para a AF

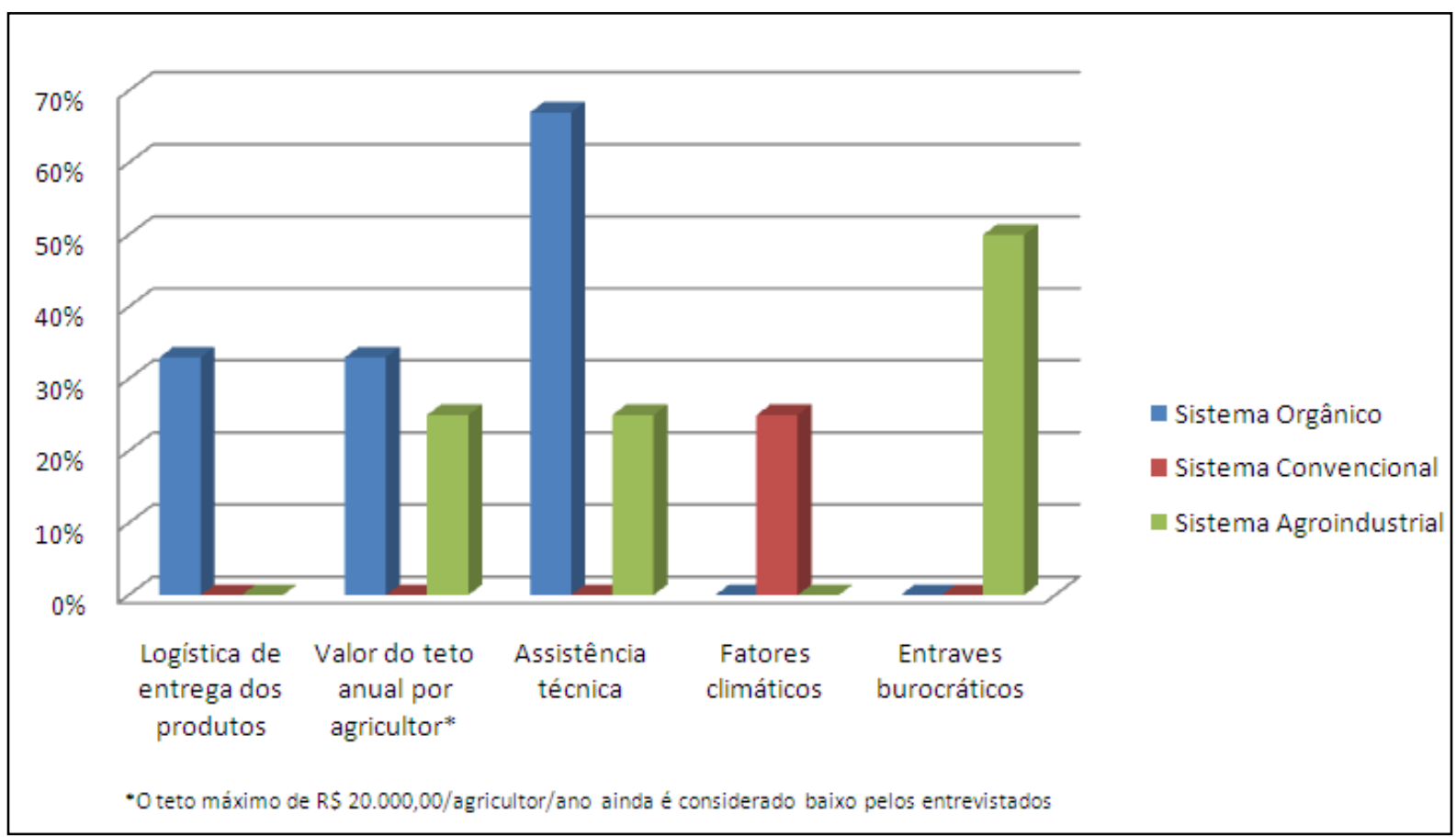

Fonte: Elaborada pela autora com base nos dados de campo (2014).

Logo, podemos considerar o PNAE como a terra fértil para a segurança alimentar e para o desenvolvimento rural, mas, junto a este pode estar correndo um risco que ainda é difícil de calcular. A relação de dependência para com o mercado institucional PNAE especialmente se atentarmos ao fato de que houve um direcionamento da produção e investimentos em estrutura e equipamentos em decorrência das demandas do programa.

Nas reflexões dos agricultores acerca da segurança deste mercado, pontualmente em um dos casos do Sistema Agroindustrial devido à concorrência em uma das Chamadas Públicas de 2013. "A experiência foi frustrante, porque quando seria um mercado certo, se tornou incerto pela concorrência de agroindústrias de fora (do município) numa chamada pública” (AGRICULTORA DA UPA 'K'). Além das considerações sobre o que significa este canal de comercialização, como exposto acima, os atores sociais que formaram o público-alvo 
deste estudo compartilham de outra percepção sobre o programa, a dificuldade com a parte burocrática ao participarem das chamadas públicas.

A estratégia que estão utilizando para lidar com este obstáculo é em alguns momentos abrir mão das atividades na UPA para se deslocar até o setor de AE e setor de compras da administração municipal para compreender e acompanhar a tramitação documental das chamadas públicas, mesmo assim permanece a insegurança, gerando alguns entraves a serem superados. Logo, a aquisição de alimentos da agricultura familiar exige um planejamento, o qual segue tramites burocráticos que beiram o excesso de formalidades, mesmo para agricultores que comercializam seus produtos para este mercado há quatro anos.

Como forma de minimizar a dificuldade dos agricultores acima mencionada, a partir da rede de conhecimento das entidades envolvidas no processo de organização desta compra foi elaborado um passo a passo, muito similar ao que foi estipulado com a abertura institucional deste mercado a partir de 2009, pelo grupo de atores sociais, que se reúne antes de cada chamada pública desde 2006. No momento desta pesquisa, as entidades envolvidas neste processo e no acompanhamento da operacionalização do PNAE são a estrutura da Prefeitura através de suas secretarias municipais de Educação, Cultura e Desporto - SMECD, da Fazenda - SMF, de Desenvolvimento Rural - SMDR; a Em ater/ASCAR, a COOPAR, o Conselho Municipal Agropecuário - CAPEC; o Conselho Municipal de Alimentação Escolar - CAE e as Associações de Agricultores.

Além deste trabalho em rede, verificou-se em 2014 que duas das quatro agroindústrias fornecedoras de alimentos para a AE foram legalizadas com o intuito de ampliar a comercialização. Conforme previsto no passo a passo elaborado pelas entidades citadas acima, o qual teve como objetivo tornar viável a compra de produtos da agricultura familiar para a alimentação escolar, houve o incentivo à formalização de agroindústrias através do PNAE em São Lourenço do Sul.

Foi apontada como novidade a partir de 2014, a realização de adequações necessárias junto à SMF, especialmente no Setor de Compras, para que passasse a ser aceita a nota fiscal de produtor rural (Modelo XV), ampliando as possibilidades de participação dos 
agricultores nas chamadas públicas. Assim, criou-se a oportunidade de aumento da aquisição de alimentos de produtores locais, beneficiando pequenos agricultores, que para Triches e Schneider (2010), concede ao PNAE um grande potencial para ser utilizado como uma política de caráter estruturante.

Com relação ao suporte de recursos humanos para atendimento da alimentação escolar da rede municipal de ensino, a estrutura do quadro de pessoal da SMECD, conta com uma coordenadora do setor de $A E$, uma nutricionista, uma secretária administrativa, três estoquistas e um motorista. Todo o trabalho desenvolvido (processo de compra, recebimento, controle de qualidade, armazenamento e entrega dos alimentos nas escolas) é acompanhado pela nutricionista e/ou coordenadora do setor de $A E$, pela coordenadora do setor de material e manutenção e pelo CAE.

Atualmente, as compras de produtos orgânicos contam com treze agricultores que entregam alimentos, através de grupo formal, representado pela Cooperativa Sul Ecológica de Agricultores Familiares Ltda. que tem sede no município de Pelotas - RS. A aquisição de produtos agroindustrializados, conta com quatro agroindústrias de São Lourenço do Sul, sendo que três entregam individualmente e uma fornece seus produtos através da Sul Ecológica. Ainda temos os produtos convencionais da AF fornecidos pela COOPAR de São Lourenço do Sul, a cooperativa informou que quarenta produtores de leite do seu quadro de associados são responsáveis pelo fornecimento da quantidade de leite em pó e bebida láctea e há a estimativa de que vinte e dois agricultores cooperados atendam o fornecimento de arroz e de feijão. Neste sistema produtivo temos ainda um agricultor que fornece morangos individualmente e outros três organizados, informalmente que fornecem hortaliças e frutas (tomate, morango, pimentão, repolho e couve).

Dentre os avanços propiciados pelo PNAE nas UPAS aparecem a ampliação de espaço físico, a aquisição de máquinas e equipamentos, a aquisição de telefones celulares para todos os integrantes da família. E, como disseram os agricultores, resultado que gera um sentimento de satisfação por produzirem e comercializarem seus produtos com a segurança de obtenção de renda (devido à venda programada, com periodicidade previamente 
combinada). Tais mudanças na vida destas famílias pode ser considerado um avanço econômico promovido por uma política pública de fomento à comercialização agrícola.

Porém, se relacionarmos a questão do sentimento de segurança quanto ao mercado institucional que apareceu várias vezes, ao fato de que o PNAE pode sofrer alterações no seu modo de execução. Por exemplo, se visualizarmos um cenário perspectivo em que sejam acrescentadas as categorias de agricultores patronais ou empresariais nas chamadas públicas resta uma dúvida: Que tipo de segurança o PNAE oferece para os agricultores familiares?

Outra reflexão que surge ao analisarmos a operacionalização do PNAE é: Onde está a autonomia destes atores sociais na execução dessa política pública de fomento ao desenvolvimento rural? Há dependência ou liberdade dos atores envolvidos na produção de alimentos para abastecimento do PNAE?

\section{Considerações finais}

A reflexão exposta até o momento abordou o tema mercado institucional PNAE e seus impactos para a agricultura familiar. $O$ estudo analisou as características de organização da produção, da família e da comercialização nas unidades de produção fornecedoras de produtos agrícolas para a alimentação escolar em São Lourenço do Sul. Para tanto, buscou sustentação na abordagem sistêmica para responder ao problema de pesquisa e alcançar os objetivos propostos junto a agricultores familiares procurando compreender os múltiplos fatores da vida, da produção e da inserção dos seus produtos aos consumidores de um mercado institucional recente.

Assim, encontramos UPAs que produzem frutas, verduras, legumes, ovos e mel (com mais de 20 gêneros alimentícios) no sistema de produção de base ecológica; outras que produzem frutas, verduras, legumes, ovos, leite e grãos como arroz e feijão (com nove gêneros alimentícios) no sistema de produção convencional e agroindústrias, uma que produz Schmiers, geléias e sucos orgânicos e as outras três de produtos convencionais, dentre eles panificados como biscoitos, cucas, pães e massas. Como resultado foi possível 
verificar que os agricultores familiares inseridos no PNAE estão organizados em grupos formais (cooperativas e associações) e informais (grupos de produtores por localidade), utilizando-se destas organizações e as agroindústrias familiares para acessar as compras governamentais.

Constatou-se que o PNAE não é o único canal de comercialização adotado pelos agricultores. Este aparece como um dos principais mercados, mas também são comercializados os produtos in natura e agroindustrializados nas lojas da Cooperativa Sul Ecológica, na COOPAR, na feira local, em feiras e eventos regionais, estaduais e nacionais, ou vendidos a domicílio. No que tange a organização e a formalização das agroindústrias, constatou-se que o PNAE foi uma das molas propulsoras. O estudo evidenciou questões como o empoderamento da mulher, a cooperação de todos os integrantes da família nos afazeres da UPA, incluído os domésticos, com a consequente inversão de papéis na unidade familiar.

A comunicação e cooperação existentes, reciprocamente entre agricultores, seus grupos formais ou informais e unidade executora do programa aparece como uma estratégia para a superação das dificuldades encontradas. Evidenciou-se, também, que o acesso a este mercado institucional, tem inspirado um cuidado maior com a produção. Além disso, constatamos que a sucessão familiar já ocorre ou está planejada para ocorrer por parte dos jovens sendo um dos motivos mencionados a segurança na comercialização.

Assim, depreendemos que as influências do PNAE podem ser consideradas significativas no modo de organização das famílias, da produção e da comercialização, sinalizando que políticas públicas de acesso à comercialização podem, num curto espaço de tempo, vir a dar indicativos de fomento à reprodução social da agricultura familiar.

Porém, cabe ressaltar que encontramos limitações diante de um universo de pesquisa tão vasto de particularidades e que emergem questionamentos como proposta para trabalhos futuros no anseio de melhor conhecer os impactos de uma política pública que fomenta o desenvolvimento rural. 


\section{Referências}

ABRAMOVAY, R. Entre Deus e o diabo: mercados e interação humana nas ciências sociais. Tempo Social, Revista de Sociologia da USP, v. 16, n. 2, p. 35-64, nov. 2004. Disponível em: $<$ http://ricardoabramovay.com/2004/10/03/entre-deus-e-o-diabo-mercados-e-interacaohumana-nas-ciencias-sociais/>. Acesso em: 21 ago. 2014.

AGNE, C. L. Agroindústrias rurais familiares e a rede de relações sociais nos mercados de proximidade da região Corede Jacuí Centro/RS. Porto Alegre, 2010. Dissertação (Mestrado em Desenvolvimento Rural, Programa de Pós Graduação em Desenvolvimento Rural, Faculdade de Ciências Econômicas) - Universidade Federal do Rio Grande do Sul, 2010.

ASTIER, M. et al. Marco para laEvaluación de Sistemas de Manejo de Recursos Naturales Incorporando Indicadores de Sustentabilidad (MESMIS). 2009. Disponível em: <http://mesmis.gira.org.mx/es/static/mesmis_framework>. Acesso em: 29 out. 2014.

BELIK, W. Perspectivas para segurança alimentar e nutricional no Brasil. Saúde e Sociedade, v. 2, n. 1, p. 12-20, jan./jun. 2003. Disponível em: <www.scielo.br/pdf/sausoc/v12n1/04.pdf> Acesso em: 6 jul. 2014.

CARNEIRO M. J. Agricultores familiares e pluriatividade: tipologias e políticas. In: COSTA, L. F. C.; BRUNO, R.; MOREIRA, R. J. (Orgs.). Mundo rural e tempo presente. Rio de Janeiro: Mauad, 1999.

CARVAlHo, D. G. de; CASTRO, V. M. de. O PNAE como Política Pública de Desenvolvimento Sustentável. VIII Encontro da Sociedade Brasileira de Economia Ecológica. Cuiabá - MT, 2009. Disponível em: <http://www.ecoeco.org.br/conteudo/publicacoes/encontros>. Acesso em: 2 jun. 2014.

CONTERATO, M. A.; NIEDERLE, P. A.; RADOMSKY, G.; SCHNEIDER, S. Mercantilização e mercados: a construção da diversidade da agricultura na ruralidade contemporânea. In: SCHNEIDER, Sérgio; GAZOLLA, Márcio. (Orgs.). Os atores do Desenvolvimento Rural: perspectivas teóricas e práticas sociais. Porto Alegre: UFRGS, 2011.

DUFUMIER. M. Projetos de Desenvolvimento Agrícola. Salvador: EDUFBA, 2007.

FOOD AND AGRICULTURE ORGANIZATION OF THE UNITED NATIONS (FAO) no Brasil Superação da Fome e da Pobreza Rural: iniciativas brasileiras. Brasília, DF: FAO, 2016. Disponível em: <https://www.fao.org.br/download/LivroFAOBrasilMemoriaCooperacao Tecnica.pdf>. Acesso em: 14 maio 2016.

GIL, A. C. Como elaborar projetos de pesquisa. 5. ed. São Paulo: Atlas, 2010. 
INSTITUTO DE PESQUISA ECONÔMICA APLICADA (IPEA). Município: São Lourenço do Sul. 2010. Disponível em: <http://www.ipeadata.gov.br/>. Acesso em 6 jun. 2014.

KLUCK, C.; GAZOLLA, M. Pronaf e Desenvolvimento Rural: estudo de caso dos agricultores familiares ecologistas do município de Antônio Prado (RS) In: COTRIM, Décio (Org.). Desenvolvimento rural e agricultura familiar: produção acadêmica da Ascar. Porto Alegre: Emater/RS-Ascar, 2014. (Coleção Desenvolvimento Rural, v. 3). 623p. Disponível em: <http://www.emater.tche.br/site/arquivos_pdf/teses//E_Book3.pdf>. Acesso em: 27 fev. 2015.

MALUF, R. S. Ações Públicas Locais de Abastecimento Alimentar. Polis Papers: Polis Assessoria, Formação e Estudos em Políticas Sociais, n. 5, 42 p., São Paulo, 1999. Disponível em: <http://www.polis.org.br/uploads/845/845.pdf>. Acesso em: 2 jul. 2014.

MINAYO, M. C. de S. Pesquisa social: teoria, método e criatividade. 30. ed. Petrópolis: Vozes, 2011.

NAZZARI, R. K.; BERTOLINI, G. R. F.; BRANDALISE, L. T. (Orgs.) Gestão das unidades artesanais na agricultura familiar: uma experiência no Oeste do Paraná. Cascavel: EDUNIOESTE, 2007.

PEIXINHO, A. A trajetória do Programa Nacional de Alimentação Escolar no período de 20032010: relato do gestor nacional. Ciênc. Saúde Coletiva, Rio de Janeiro, n. 4, v. 18. p. 909-916, abr., 2013. Disponível em: <http://www.scielo.br/pdf/csc/v18n4/02.pdf>. Acesso em: 6 jun. 2014.

SABOURIN, E.; SAMPER, M.; MASSADIER, G. Políticas públicas para as agriculturas familiares: existe um modelo latino-americano? In: GRISA, C.; SCHNEIDER, S. (Orgs.) Políticas públicas de desenvolvimento rural no Brasil. Porto Alegre: UFRGS, 2015.

SILIPRANDI, E; CINTRÃO, R. Mulheres rurais e políticas públicas no Brasil: abrindo espaços para o seu reconhecimento como cidadãs. In: GRISA, C.; SCHNEIDER, S. Políticas públicas de desenvolvimento rural no Brasil. Porto Alegre: UFRGS, 2015.

TRICHES, R. M.; SCHNEIDER, S. Alimentação Escolar e Agricultura Familiar: reconectando o consumo à produção. Saúde e Sociedade, São Paulo, n. 4, v. 19, p. 933-945, 2010. Disponível em: <http://dx.doi.org/10.1590/S0104-12902010000400019>. Acesso em: 27 maio 2014.

TRICHES, R. M.; GERHARDT, T. E.; SCHNEIDER, S. Políticas alimentares: interações entre saúde, consumo e produção de alimentos. Interações. Campo Grande, v. 15, n. 1, p. 109-120, jan./jun., 2014. Disponível em: <http://www.scielo.br>. Acesso em: 24 jul. 2015.

WIVES, D. G. Fatores influentes na tomada de decisão e organização dos sistemas de produção de base ecológica da banana no Litoral norte do Rio Grande do Sul. Porto Alegre, 2013. Tese (Doutorado em Desenvolvimento Rural) - Faculdade de Ciências Econômicas, Universidade Federal do Rio Grande do Sul, 2013. 